\title{
STUDIES ON INBREEDING
}

II. THE EFFECTS OF INBREEDING ON THE FERTILITY AND ON THE CONSTITUTIONAL VIGOR OF THE ALBINO RAT

HELEN DEAN KING

The Wistar Institute of Anatomy and Biology

$$
\text { TWO CHARTS }
$$

The present paper gives data showing the fertility and the constitutional vigor in a strain of albino rats that was inbred, litter brother and sister, for twenty-five successive generations.' Details regarding the manner in which these experiments were conducted and data for the growth and variability in the body weight of inbred rats have already been published (King, '18a).

\section{THE FERTILITY OF INBRED RATS}

As shown by a number of recent investigations (Pearson et al., '99; Rommell and Phillips, '06; Pearl, '12, a, and Wentworth, '16), fertility is undoubtedly a racial character that is transmitted by inheritance, although it is influenced to a considerable extent by a variety of extraneous factors. The mode of inheritance of fertility in the rat is not discussed in the present instance, since the effects of inbreeding on fertility is the chief subject under consideration.

Throughout this paper the word 'fertility' is used as defined by Pearl and Surface ('02) to designate: "The total actual reproductive capacity of pairs of organisms, male and female, as expressed by their ability when mated together to produce (i.e., bring to birth) individual offspring." According to this view, fertility depends upon and includes fecundity as well as a great number of other factors. As Pearl and Surface state: "Clearly it is fertility rather than fecundity which is measured in statistics of birth of mammals." 
The inbred strain of rats was composed of two series, A and B, . both derived from the same ancestral stock. In every generation of each series the females that were used for breeding were paired twice with a brother from the same litter, thus producing the strictly 'inbred' litters that alone furnished the breeding stock in the following generation. These same females were then paired twice with an unrelated Albino male taken from the general stock colony. For convenience, litters with the latter parentage are here designated as 'half-inbred' litters.

The early generations of these inbred animals suffered severely from malnutrition, due to improper feeding. Nutritive conditions were improved after the fourth generation, and the animals quickly regained their normal size and fertility. At no stage of the investigation was any attempt made to influence the productiveness of the animals, other than by keeping them under environmental and nutritive conditions that were as uniform and as favorable as it was possible to make them.

\section{A. Litter size}

The normal fertility of any race can properly be estimated only from the total number of offspring produced by many females during the entire period of their reproductive activity. The fertility in the inbred strain of rats cannot be measured by this standard, unfortunately, since the plan of the experiment called for only four litters from each breeding female, and after this number was obtained the females were usually discarded. According to Crampe ('84), the Albino female has, on the average, only three or four litters. On this basis the litter data obtained for the inbred series shows the total productiveness of the greater proportion of the females that were used for breeding. Crampe's estimate for litter production is, I believe, too low, since the breeding history of a considerable number of stock Albinos, recently obtained, shows that the females had an average of 5.3 litters each. Records for the inbred series undoubtedly cover the most productive period in the life of the females, and if the fertility of the strain was impaired to any extent by inbreeding it is probable that all of the litters cast would have been smaller than normal. 
The number and average size of the litters produced in each of the first twenty-five generations of the A series of inbreds are given in table 1. Similar data for the litter production in the B series of inbreds are shown in table 2.

These tables are inserted chiefly for reference, but a comparison between corresponding data indicates clearly that the fertility of the animals in one inbred series was about the same as that in the other series. The summary of the data for the two series shows that the 1752 litters in the A series contained an average of 7.5 young, while the 1656 litters in the $B$ series had an average of 7.4 young. This close agreement in the records for two such large groups of animals is doubtless due to the fact that all of the inbred rats were descended from the same ancestral stock and that individuals in corresponding generations of the two series were reared simultaneously under similar environmental conditions.

The data in table 1 and in table 2 have been combined in table 3 , which thus shows the number and average size of the litters produced in the first twenty-five generations of the inbred strain. The data given comprise the records for 3408 litters containing 25,452 individuals.

To facilitate the discussion of the effects of inbreeding on fertility the data given in table 1 to table 3 were combined by generation groups. There were relatively few individuals in the first six generations of inbreds and their data were united to form the first group, since the character of the experiment was changed at this point. Data for subsequent generations were divided into five groups, each of which, with the exception of the last, comprised the records for four successive generations. Such a division of the data was, of course, purely arbitrary, but it seemed the most satisfactory arrangement possible. A group of four generations covers approximately the litter production for one year, and as the number and size of the litters vary considerably at different times of the year, this grouping assured a uniform distribution of the seasonal variations in litter size among all of the various groups.

Litter data for the A series of inbreds, arranged according to generation groups, are given in table 4. 


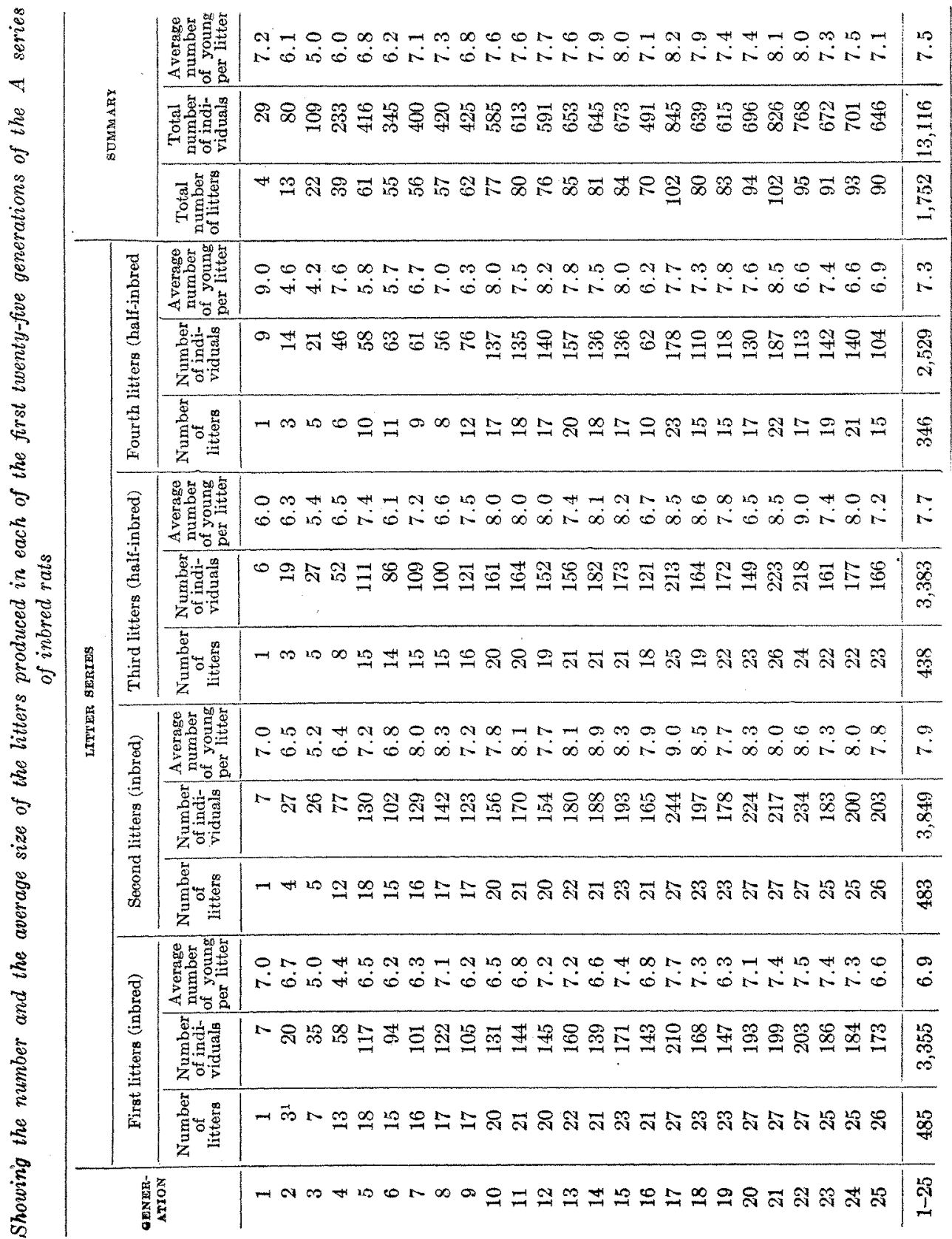




\begin{tabular}{|c|c|c|c|c|c|}
\hline 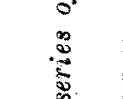 & & & 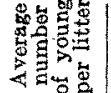 & 虽 & $\stackrel{\square}{\sim}$ \\
\hline $\begin{array}{l}\infty \\
\$ \\
\Xi\end{array}$ & 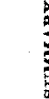 & & 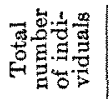 & 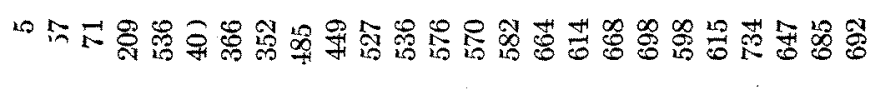 & $\begin{array}{l}\mathscr{8} \\
\stackrel{0}{్}\end{array}$ \\
\hline 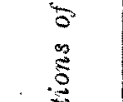 & & & 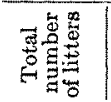 & 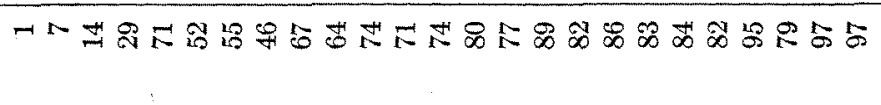 & $\begin{array}{l}0 \\
0 \\
-1 \\
-1\end{array}$ \\
\hline 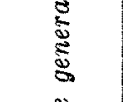 & & $\begin{array}{l}\text { 总 } \\
\text { 点 }\end{array}$ & 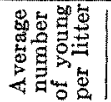 & 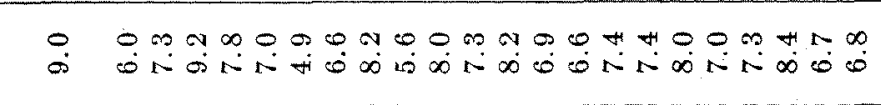 & $\stackrel{9}{N}$ \\
\hline 胥 & & 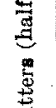 & 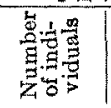 & 。 & 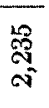 \\
\hline $\begin{array}{l}5 \\
5 \\
5 \\
5 \\
5\end{array}$ & & 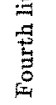 & 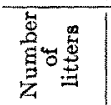 & 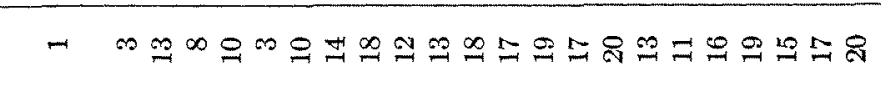 & $\hat{今}$ \\
\hline 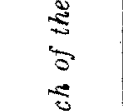 & & 氶 & 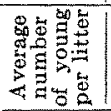 & 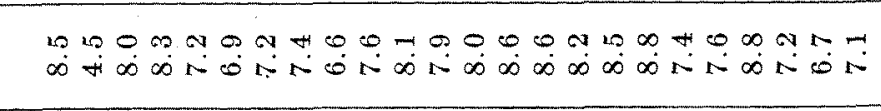 & $\stackrel{\infty}{\sim}$ \\
\hline 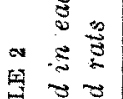 & & 竘 & 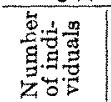 & 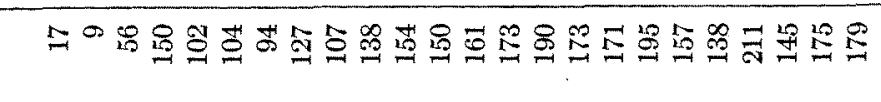 & $\begin{array}{l}0 \\
\text { s. } \\
\text { on } \\
0\end{array}$ \\
\hline 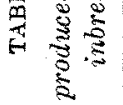 & 器 & 节 & 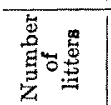 & N NN舫里品 & $\stackrel{9}{7}$ \\
\hline : & 笣 & 马्\zh14̆ & 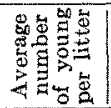 & 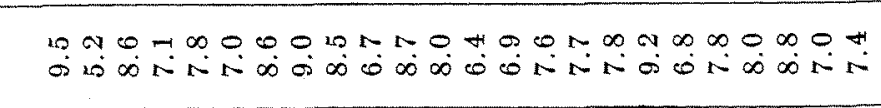 & $\stackrel{\infty}{\infty}$ \\
\hline $\begin{array}{l}2 \\
3 \\
\infty \\
0\end{array}$ & & 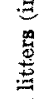 & 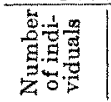 & 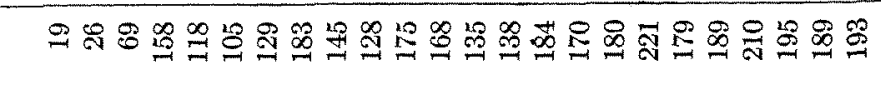 & 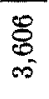 \\
\hline$\stackrel{3}{3}$ & & $\begin{array}{l}\text { 若 } \\
\text { 惫 }\end{array}$ & 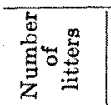 & 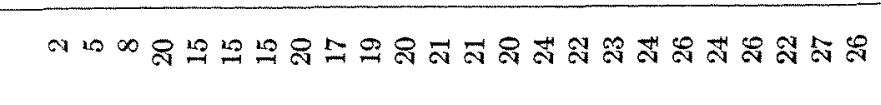 & 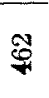 \\
\hline$\Xi$ & & 畺 & 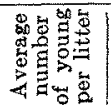 & 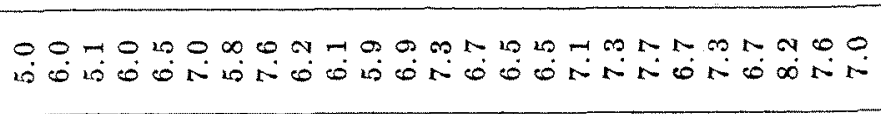 & $\stackrel{0}{0}$ \\
\hline ఏ & , & 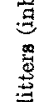 & 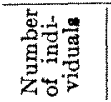 & 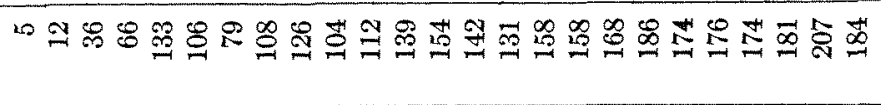 & $\underset{\sim}{\stackrel{9}{\text { స }}}$ \\
\hline 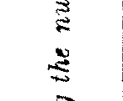 & & 夢 & 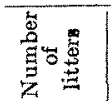 & - N & $\stackrel{\infty}{\&}$ \\
\hline$\frac{5}{5}$ & & 骨 & & - & జิ \\
\hline
\end{tabular}




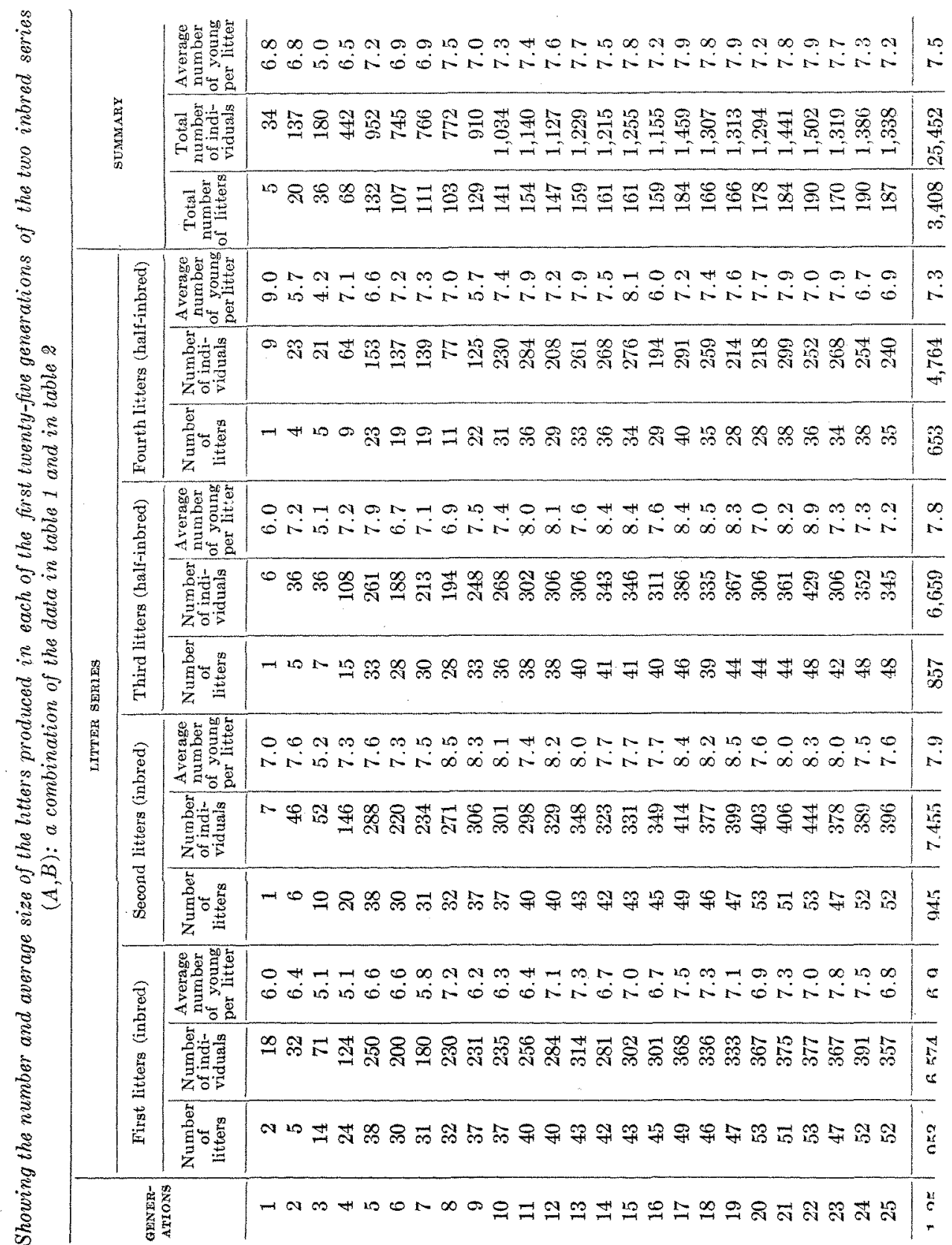




\begin{tabular}{|c|c|c|c|c|c|}
\hline & & & 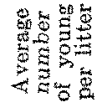 & ง ฯ & 2 \\
\hline 焉 & & & 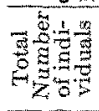 & 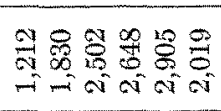 & 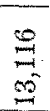 \\
\hline 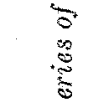 & & & 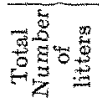 & 式怘命员志芯 & i \\
\hline$\underset{\$}{\$}$ & & $\frac{3}{8}$ & 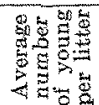 & 0 & 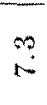 \\
\hline 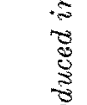 & & 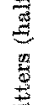 & 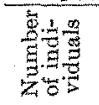 & 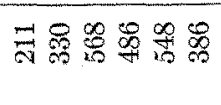 & 赵 \\
\hline 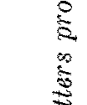 & & 吾 & 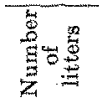 & 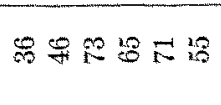 & 总 \\
\hline 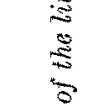 & & 焉 & 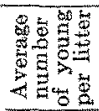 & $\begin{array}{lllll}0 & 0 & 0 \\
0 & 0 & 0 & 0 & 0\end{array}$ & 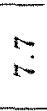 \\
\hline 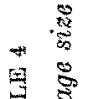 & & 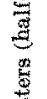 & 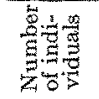 & 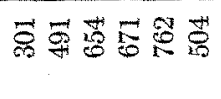 & $\begin{array}{l}\mathscr{B} \\
\infty \\
\infty\end{array}$ \\
\hline 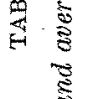 & 喼 & 总 & 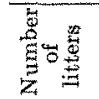 & $18 \overrightarrow{0080}$ & $\stackrel{\infty}{\mathscr{G}}$ \\
\hline 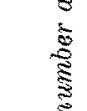 & 篅 & 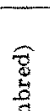 & 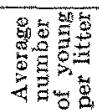 & $\begin{array}{l}\infty \\
\infty N \infty<\infty\end{array}$ & 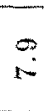 \\
\hline 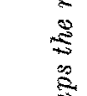 & & 总 & 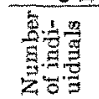 & 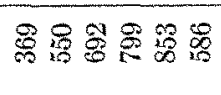 & $\begin{array}{l}\text { 艁 } \\
\text { - }\end{array}$ \\
\hline $\begin{array}{l}\text { : } \\
\text { s } \\
:\end{array}$ & & 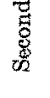 & 要照 & 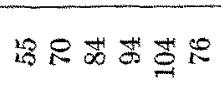 & $\frac{8}{8}$ \\
\hline 童 & & छ্ & 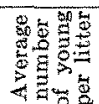 & $\begin{array}{l}\infty \\
100 \\
100 \mathrm{~N}\end{array}$ & 0 \\
\hline 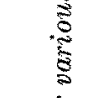 & & 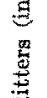 & 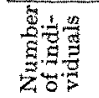 & 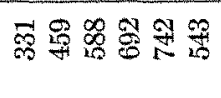 & 象 \\
\hline 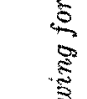 & & 喆 & 要影 & 的只芯芯苍杲 & $\stackrel{20}{\infty}$ \\
\hline$\frac{3}{2}$ & & & & 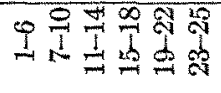 & $\stackrel{39}{19}$ \\
\hline
\end{tabular}


An examination of table 4 shows that all of the litters produced in the first generation group of the A series were smaller, on the average, than corresponding litters in the later generation groups. The relatively low fertility of the animals in the early generations was not due to inbreeding, but to the fact that these individuals suffered from malnutrition. As soon as the nutritive conditions were improved there was at once an increase in the number and in the size of the litters produced, as the data for the fifth and for the sixth inbred generations show (table 1).

As indicated in the last column of table 4 , the groups comprising the tenth to the twenty-fifth generations of the $A$ series showed, as a whole, comparatively little variation in the average size of the litters. The maximum average size (7.8) came in the group including the fifteenth to the eighteenth generations. This maximum was, however, only 0.1 greater than the average litter size for the preceding and for the following group, and therefore it can have little, if any, significance.

Litter data for various generation groups in the B series of inbreds are shown in table 5 .

As the average size of the litters produced in the first generation group was greater than that in the second group (table 5), it might appear that the fertility of the breeding females in the $B$ series was not lessened by malnutrition. In the beginning of these experiments many more females of the $B$ series than of the A series were completely sterile, but the females of the B series that did breed were the more productive. Malnutrition, in this instance, was a selective agent that helped to eliminate the tendency to sterility in the $B$ series by preventing the breeding of any except the most fertile females.

In the $B$ series the maximum average size of the litters was found in the group comprising the nineteenth to the twentysecond generations, but, as was the case in the A series, this maximum was not great enough to be considered significant.

Litter data given in table 4 and in table 5 have been combined in table 6.

The data for each of the two inbred series, as well as that given in table 6 , shows that in all generation groups the first litter cast 
EFFECTS OF INBREEDING ON FERTILITY AND VIGOR 343

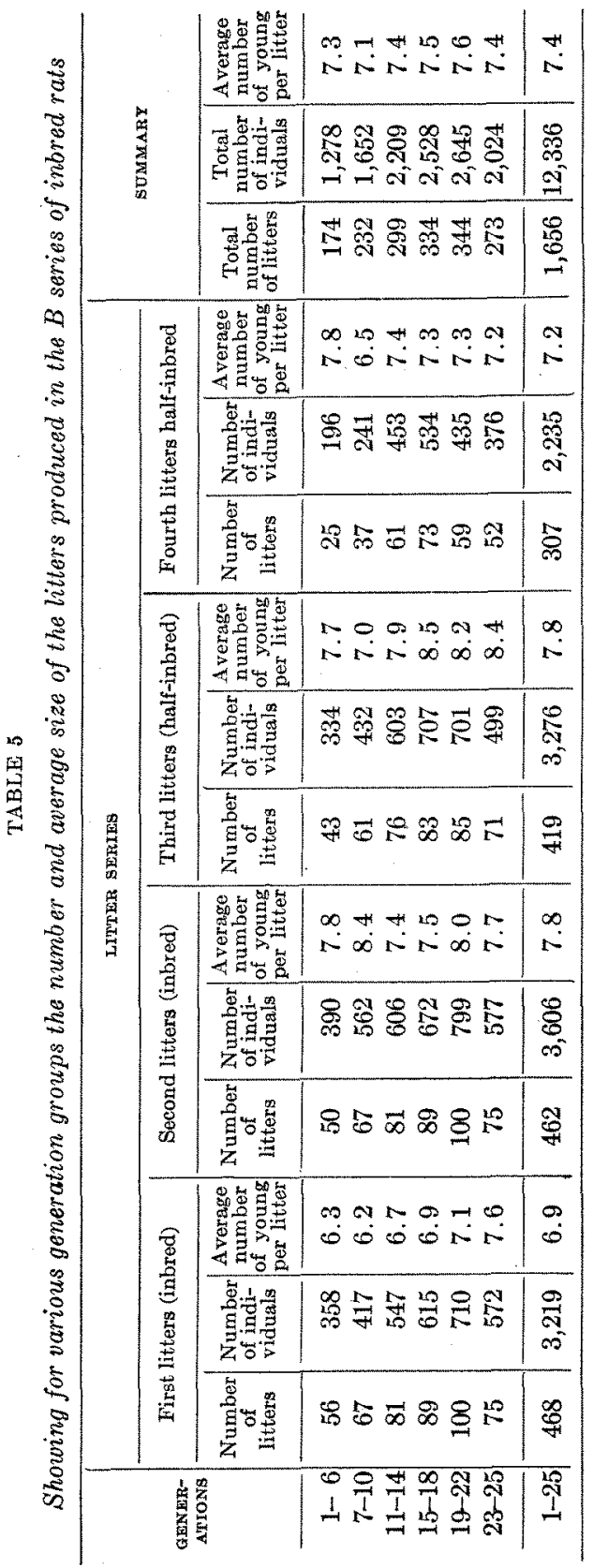




\begin{tabular}{|c|c|c|c|c|c|}
\hline \multirow{3}{*}{\multicolumn{2}{|c|}{$z$}} & & 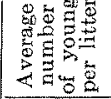 & $0 \leadsto$ & $\stackrel{n}{n}$ \\
\hline & & & 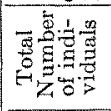 & 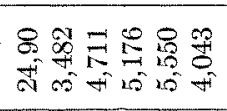 & $\begin{array}{l}9 \\
\text { io } \\
\text { is } \\
\text { of }\end{array}$ \\
\hline & & & 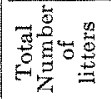 & 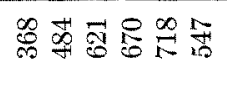 & $\stackrel{\infty}{\stackrel{+}{+}}$ \\
\hline 芯 & & 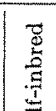 & 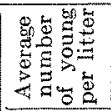 & $\begin{array}{l}000+0 H \\
00 N \mathbb{N}\end{array}$ & $\stackrel{?}{\sim}$ \\
\hline 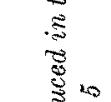 & & 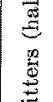 & 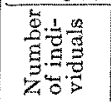 & 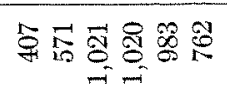 & 苍 \\
\hline 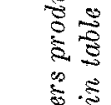 & & 吾 & 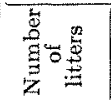 & 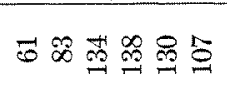 & 80 \\
\hline 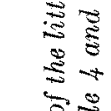 & & 蔍 & 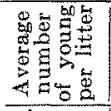 & $\begin{array}{l}0 \\
N N \infty\end{array}$ & $\stackrel{\infty}{\infty}$ \\
\hline 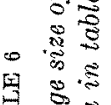 & & 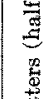 & 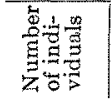 & 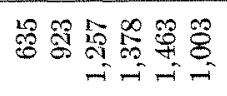 & : \\
\hline 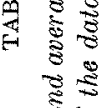 & 嘿 & 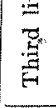 & 要 & 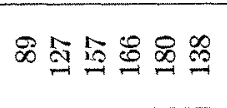 & $\frac{5}{\infty}$ \\
\hline 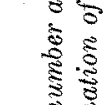 & 策 & 总 & 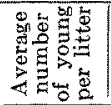 & 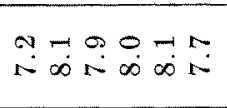 & $\stackrel{9}{N}$ \\
\hline 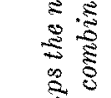 & & 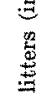 & 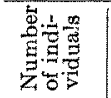 & 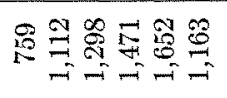 & $\begin{array}{l}\text { 量 } \\
\text { s }\end{array}$ \\
\hline 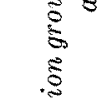 & & 造 & 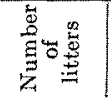 & 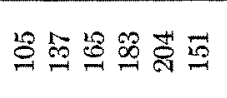 & $\frac{28}{5}$ \\
\hline 宽 & & 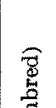 & 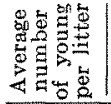 & 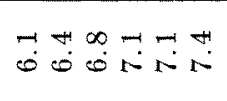 & 0 \\
\hline$\frac{a}{3}$ & & 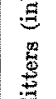 & 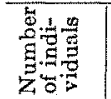 & $\begin{array}{ll}80 \\
0 \\
0\end{array}$ & $\begin{array}{l}7 \\
1 \\
6 \\
0\end{array}$ \\
\hline 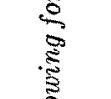 & & 营 & 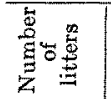 & 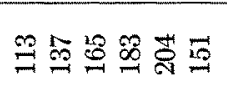 & : \\
\hline 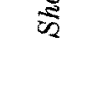 & & & & 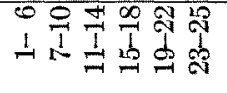 & $\stackrel{10}{1}$ \\
\hline
\end{tabular}


was the smallest in the litter series, as a rule; the second litter was the largest; the third and fourth litters were intermediate in size between the first and the second; a similar relation in the size of litters has been found, also, in two groups of stock Albinos. In both inbred series the first two litters cast in each generation were the offspring of brother and sister matings; the third and fourth litters were produced by the mating of an inbred female with an unrelated stock male. In the first of the stock series noted (King and Stotsenburg, '15, table 7) all of the litters were produced by the pairing of unrelated stock animals; in the second stock series, for which data are given in table 7 of the present paper, all of the litters obtained were the offspring of brother

TABLE 7

Showing the average size of each of the first four litters produced by a series of stock Albino females

\begin{tabular}{c|c|c|c}
\hline LITTER 'SEREES & NUMBER OF LITTERS & NUMBER OF INDIVIDUALS & $\begin{array}{c}\text { AVERAGE NUMBER OF } \\
\text { YOUNG PER LITTER }\end{array}$ \\
\hline 1 & 116 & 717 & 6.2 \\
2 & 116 & 843 & -7.3 \\
3 & 103 & 671 & 6.5 \\
4 & 89 & 587 & 6.6 \\
\hline & 424 & 2818 & 6.7 \\
\hline
\end{tabular}

and sister matings. Since in all three groups the average size of the litters in the litter series varied in a similar way, it is evident the litter size does not depend at all on the relatedness or the unrelatedness of the parents, but chiefly on the age of the female. Young females tend to be somewhat less prolific than older ones, as Crampe ('83) noted. The litters reach their maximum size when the females are about five months old, but the number of young does not decrease appreciably in the various litters cast until the females have passed the height of their reproductive power at about seven months of age (King, '16b).

As shown in the first paper of this series (King, '18), the rats in the seventh to the ninth inbred generations were considerably heavier, at any given age, than the individuals belonging to subsequent generations. The cause for this unusually vigorous 
growth was attributed to a stimulation of the growth processes produced by adequate nutrition following a period of semistarvation. During this period the productiveness of the females was increased considerably, since the average size of the litters in the group comprising the seventh to the tenth generations was 0.4 greater than the average for the previous generation group (table 6). The period of maximum fertility in the inbred series did not, however, coincide with the period of maximum growth in body weight, but came at a much later time (fifteenth to the twenty-second generations), when the litters contained 7.7 young, on the average. The fact that the average size of the litters in the last three generations of the inbred series was slightly lower than the maximum can be attributed to a change in diet made necessary by the economic conditions of the present time. This diet does not seem to be quite as favorable to growth and fertility as was the more varied diet used until the beginning of last year.

The graph in figure 1, showing the average size of the litters produced in the various generations of the inbred strain, was constructed from the data in the last column of table 3.

Starting at the point of 6.8 , the graph in figure 1 drops at the third generation to 5.0, the lowest point in its course. From this point it rises slowly, and after the fifth generation tends to be a fairly horizontal line, since it never falls below 6.9 nor does it rise above 7.9. At more or less regular intervals the graph drops slightly below the normal level. The most pronounced depression is at the point of the third generation; a second drop comes at the ninth generation; other depressions of about the same depth are found at the point of the sixteenth, the twentieth, and the twenty-fourth generations. As the last three depressions in the graph occur at intervals of four generations, it is evident that they were not due to a chance variation in the data, but that they must express periodic changes in the reproductive cycle of the females that tended to reduce the number of young born. In whatever way this reduction was effected, whether by a lessening of fecundity or by limiting the number of embryos that were capable of normal development, the cause for it, I believe, lay in the seasonal changes in temperature which always have a marked effect on the 
physical condition of the animals. During the summer months rats suffer severely from excessive humidity and from high temperature, since their mechanism for heat regulation, under these conditions, is inadequate. At this season their sexual activity is at its lowest point, and the litters that are produced tend to be relatively small. Severe cold checks reproduction, but litters born under these conditions are usually of normal size and the

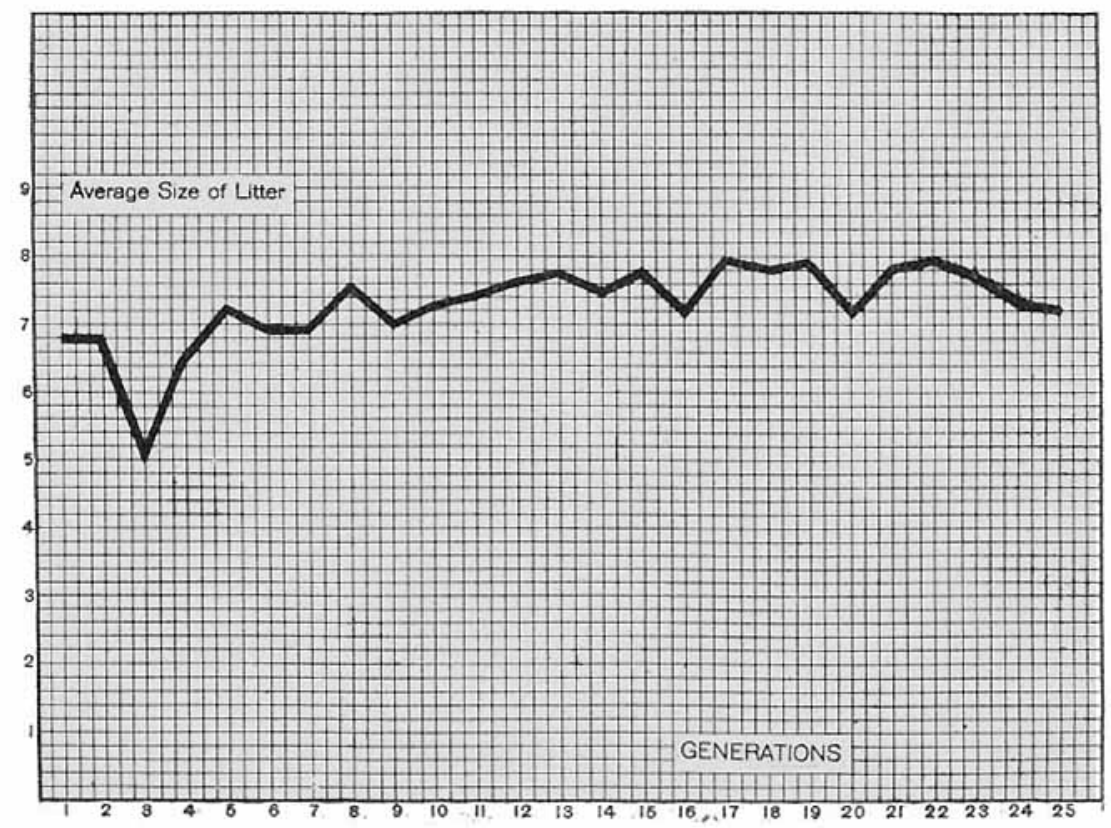

Fig. 1 Graph showing the average size of the litters produced in the various generations of the inbred strain (data in table 3 ).

individuals strong and vigorous. At about every fourth generation the majority of litters produced in the inbred strain were born at the most unfavorable season of the year, the summer and early fall. In this generation, as the records show, the litters were smaller, as a rule, than the litters in the preceding and in the following generations. This decrease in size was sufficient to account for all of the depressions in the graph in figure 1, except the first one, which was doubtless due to the fact that the maxi- 
mum effect of malnutrition in lowering the fertility of the females was reached at the third generations.

Cyclic changes in productiveness were noted by Castle et al. ('06) in an inbred strain of Drosophila, in which, for three successive years, there was a gradual rise in fertility followed by an abrupt decline. These changes in productiveness were likewise ascribed to the variations in temperature at different seasons of the year.

The data given in table 1 to table 6 and the graph in figure 1 show clearly that, despite all theories to the contrary, it is possible to maintain a high degree of fertility in a mammal for at least twenty-five generations of the closest possible form of inbreeding, by a careful selection of breeding stock and by keeping the animals under environmental conditions that are favorable for their growth and reproduction.

While, in general, the size of the litter varies according to the age of the mother, individual females differ greatly regarding the number of offspring that they produce in any litter of the litter series. Sisters from the same litter, mated to the same male, will show marked variations in their fertility at the same age. One female may never have a litter that contains more than five young; the other may always throw litters in which there are nine or more young. Some females, regardless of their age, tend to cast the same number of offspring in every litter. One female so noted had ten young in each of her four litters. Marked individual differences in fertility are also found among female guinea-pigs, according to Minot ('92).

The average number of young in a litter of albino rats is 6.3 , according to the data for 394 litters collected by Crampe ('84); Cuénot ('99) found an average of 8.5 young in the 30 litters that he examined. Records for 1089 litters of stock Albinos born in the Wistar Institute animal colony during the years 1911 to 1914 give 7.0 as the average number of young per litter (King and Stotsenburg, '15). When this last series of data was collected it was not realized that litter size in the rat depends to such a marked degree upon the age of the mother, and that in this species the maximum fertility comes at a relatively early age, as it does 
in the human race (Powys, '05) and also in poultry (Pearl, '17). Most of the litters recorded were cast by young females that had not reached the height of their reproductive power; such litters tend to be larger than those cast after this time (King, '16b). Data for litters cast by females of unknown age, however extensive they may be, cannot, therefore, properly be used to furnish the norm for litter size in the albino rat.

In order to obtain standards for litter size with which the data in the inbred strain might justly be compared, the complete breeding history of a considerable number of stock Albino females was recorded during the past three years. Data for the first four litters produced by 116 females belonging to this group are given in table 7. All of the stock rats from which these litters were obtained were reared under the same environmental conditions as the inbred strain.

In table 7 , as has already been noted, the litters of the series bear the same size relation to each other as that found in the litter series of the inbred rats. The first litter was the smallest, averaging 6.2 young; the second litter, with an average of $7.3 \mathrm{mem}-$ bers, was the largest of the series; while the third and fourth litters were somewhat smaller than the second. The entire series of 424 litters gave an average of 6.7 young per litter. This average is 0.3 less than that in the random collection of stock litters previously recorded (7.0), and 0.4 more than the norm as given by Crampe (6.3), so it is probably a fair standard for litter size in any similar series of Albino litters. There is no reason to believe that the stock females from which the litters recorded in table 7 were obtained were, as a group, inferior in reproductive power to other stock females, and presumably their fertility at any given age is fairly representative of that in the general run of stock Albinos.

Each litter of the stock series, shown in table 7, contained a smaller average number of young than the corresponding litter in either of the two inbred series when the data were arranged according to generation groups (tables 4 and 5), and, omitting the records for the first five generations where the fertility was lessened by malnutrition, there was not a single generation in either 
of the inbred series where the average size of the first four litters was as low as that in the stock series (tables 1 and 2). In the inbred series as a whole, the average size of the litters was 0.8 greater than that in the stock series. Even if the previous finding of 7.0 be taken as the norm for litter size in the rat, the difference between the average size of the litters in the inbred strain and the norm chosen is 0.5 . This difference is great enough to preclude the possibility that it was due to chance, and it cannot be attributed to the differential action of environment, since stock and inbred rats were constantly under the same environmental conditions. According to these findings, fertility in the inbred strain of Albinos, in as far as it may be judged by the size of the first four litters cast by a large number of females, was greater than the fertility in stock Albinos that were not inbred.

\section{B. Frequencies of litter size}

According to the several series of observations that have been recorded, there is a wide range in the size of the litters cast by Albino females. Kolazy (71) reports litters containing from five to seventeen young, although Crampe ('84) states that he never found even fourteen young in a litter of albino rats. Litter size varied from four to twelve in the series of Albinos studied by Kirkham and Burr (15); while in the litters recorded by King and Stotsenburg ('15) the range in size was from two to fourteen.

Data for litter frequencies in the two series of inbred rats are shown in table 8 .

TABLE 8

Showng the frequencies of litter size in the two series of inbred rats

\begin{tabular}{|c|c|c|c|c|c|c|c|c|c|c|c|c|c|c|c|c|c|}
\hline & \multicolumn{17}{|c|}{ SIZE OF LITTER } \\
\hline & 1 & 2 & 3 & 4 & 5 & 6 & 7 & 8 & 9 & 10 & 11 & 12 & 13 & 14 & 15 & 16 & 17 \\
\hline A & 1 & 40 & 59 & 103 & 193 & 182 & 288 & 268 & 258 & 181 & 99 & 45 & 27 & 5 & 2 & 0 & 1 \\
\hline$B$ & 0 & 35 & 72 & 102 & 168 & 206 & 263 & 260 & 208 & 152 & 110 & 49 & 22 & 6 & 3 & 0 & 0 \\
\hline & 1 & 75 & 131 & 205 & 361 & 388 & 551 & 528 & 466 & 333 & 209 & 94 & 49 & 11 & 5 & 0 & 1 \\
\hline
\end{tabular}


In the $A$ series of inbreds the range in litter size was from one to seventeen. The litter of one was cast by a female of the nineteenth generation that was suffering from pneumonia and had to be killed three days after parturition. This is undoubtedly a case where the physical condition of the female prevented the normal development of all of the embryos except one; the other embryos probably became atrophic and were absorbed. The litter containing seventeen members occurred in the fifteenth generation. All of the individuals were born alive, but they were all very small, weighing not more than three grams each: the average weight of the albino rat at birth is about four grams (King, '15b).

In the $\mathrm{B}$ series, as table 8 shows, the range of variation in litter size was not as great as that in the A series: no litters smaller than two or larger than fifteen were obtained. In both series litters containing seven young were the most frequent, while those with eight young were only slightly less in number.

Figure 2 shows graphs for litter frequencies in the two series of inbreds that were constructed from the data given in table 8 .

In figure 2 each graph rises quickly to the modal point at seven, falls slowly at first and then rapidly. The drop in graph $A$ at the point of 6 has apparently no significance, since there is no similar drop in the B graph. Each graph is a simple frequency curve with one modal point, and is exactly the sort of graph that one would expect to obtain from the data for litter frequencies in a large series of animals belonging to a pure race.

\section{Puberty}

Under normal conditions puberty tends to appear at approximately the same age in the different individuals of a given race, but the time of its appearance is seemingly more dependent on the growth changes incident to age than it is on age itself.

In the albino rat both males and females attain sexual maturity when they are about two months of age (Donaldson, '15), but the environmental and nutritive factors that hasten or retard growth have considerable influence on the reproductive activity of the

THE JOURNAL OF EXPERIMUNTAL, ZOÖLOGY, vOL. 26 , NO. 2 


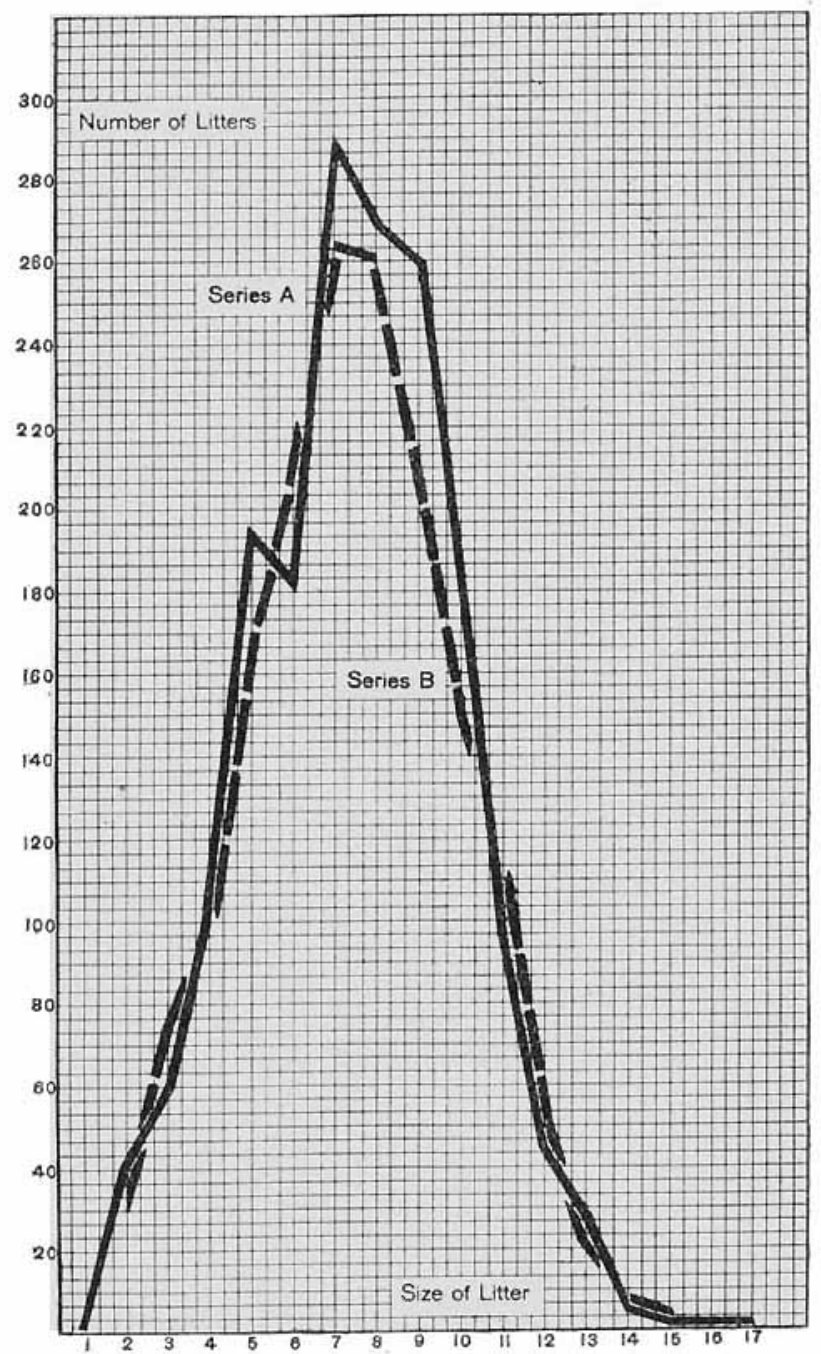

Fig. 2 Graphs showing the frequencies of litter size in the two series of inbred rats (data in table 8 ). 
individuals. If young rats are fed exclusively on a meat diet, puberty is considerably delayed (Watson, '06); the same effect is produced by underfeeding (Osborne, Mendel and Ferry, '17). According to my observations, the time of year in which the animals are born affects their subsequent growth and also the time of their maturing. Rats born in the winter and early spring grow rapidly, and usually breed at about three months of age; those born in the summer and autumn grow more slowly and comparatively few of the females cast litters before they are four months old, many not breeding until spring, which is the season of the most pronounced sexual activity for the rat. Convincing evidence that age alone does not determine the beginning or the end of the reproductive life of the rat is given by Osborne and Mendel ('15, '17), who found that Albino females, stunted at an early age by underfeeding, were completely sterile until they were properly nourished, when they grew rapidly, attained a normal size, and were able to breed long after the age at which the menopause usually appears.

According to Darwin ('75) and others, favorable environment tends to delay sexual maturity, though not necessarily to decrease fertility. Since these inbred rats were reared, for the most part, under environmental conditions that seemed well adapted to their needs, and since they lacked the stimulus to reproductive vigor which is said to come from outcrossing, it might be expected that they would tend to mature much later than stock Albinos which were not inbred.

Table 9 shows the approximate age at which the breeding females belonging to various generation groups of the two inbred series cast their first litter.

The records for the first generation group, given in table 9 , confirm Osborne and Mendel's findings that underfeeding tends to retard sexual maturity, since they show that about one-half of the breeding females in this group did not cast their first litter until they were four months old. In subsequent generations, when the animals were adequately nourished, they began breeding at a much earlier age. Under the conditions of this experiment, inbreeding seemingly hastened the onset of puberty, for 
in both series, as the inbreeding advanced, there was a marked tendency for relatively more of the females to breed at the earliest possible age. About 30 per cent of the breeding females in the eighteenth to the twenty-fourth generation group of each series threw their first litter at or before the age of ninety days; only a small proportion of them failed to breed before reaching the age of four months.

As a whole, the females of the $A$ series of inbreds tended to mature slightly earlier than the females of the B series, but the

TABLE 9

Showing the approximate age at which breeding females in various generation groups of the two inbred series ( $A$ and $B$ ) cast their first litters

\begin{tabular}{|c|c|c|c|c|c|c|c|c|c|c|c|c|}
\hline \multirow[b]{2}{*}{ 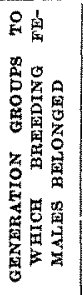 } & \multicolumn{4}{|c|}{ SERIES A } & \multicolumn{4}{|c|}{ SERTES B } & \multicolumn{4}{|c|}{$\operatorname{SUMMARX}(A, B)$} \\
\hline & 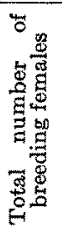 & 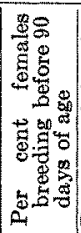 & 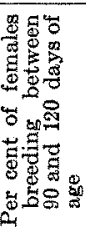 & 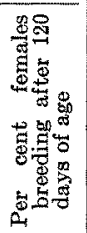 & 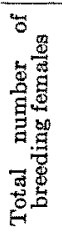 & 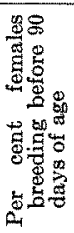 & 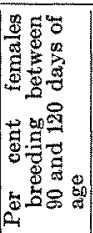 & 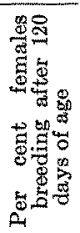 & 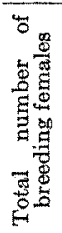 & 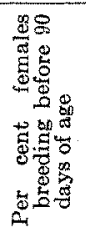 & 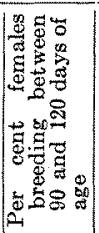 & 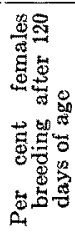 \\
\hline $1-5$ & 58 & 12.0 & 36.2 & 51.8 & 56 & 14.3 & 41.1 & 44.6 & 114 & 13.1 & 38.7 & 48.2 \\
\hline & 70 & 21.4 & 68.6 & 10.0 & 67 & 7.4 & 74.7 & 17.9 & 137 & 14.6 & 71.6 & 13.8 \\
\hline $10-13$ & 84 & 25.0 & 71.4 & 3.6 & 81 & 13.6 & 74.1 & & 16 & 19.3 & 72.8 & 7. \\
\hline $14-17$ & 94 & 28.7 & 62.8 & 8. & 89 & 25.8 & 62.9 & 11. & 183 & 27.3 & 62.9 & 9 . \\
\hline $18-21$ & 104 & 36.5 & 62.6 & 0.9 & 100 & 31.0 & 64.0 & 5.0 & 204 & 33.8 & 63.3 & 2.9 \\
\hline $22-24$ & 76 & 31.5 & 60.6 & 7.9 & 75 & 20.0 & 69.4 & 10.6 & 151 & 25.8 & 65.0 & 9.2 \\
\hline $1-24$ & 486 & 27.1 & 61.6 & 11.3 & 468 & 19.8 & 65.3 & 14.9 & 954 & 23.5 & 63.4 & 13.1 \\
\hline
\end{tabular}

difference between the two series was not great, and corresponding records were in nearly as close agreement as were those for litter size.

The youngest breeding female in the inbred strain was a member of the A series of inbreds, and she was eighty days old when she cast her first litter of five young. As the gestation period in the albino rat is about twenty-two days (Donaldson, '15), this female must have conceived when she was two months old. Kirkham and Burr ('15) state that one of their Albino females gave birth to a litter when she was only seventy-seven 
days old; while Lantz ('10) reports a case in which an albino rat was said to have produced a litter at the age of fifty-six days. This last case is certainly a remarkable one, and its parallel has not been found among the 50,000 rats bred in our colony.

The last section of table 9 shows that, after the tenth generation, there was no marked change in the proportion of females that bred at three and at four months of age, respectively. Nearly 24 per cent of the total number of females used for breeding east their first litter by the time they were three months old; over 60 per cent of them bred for the first time when they were between ninety and one hundred and twenty days of age; while about 13 per cent did not breed until after they were four months old. The latter group was made up, for the most part, of females that were born in the summer or autumn.

Although Düsing ('84) states that inbred animals tend to mature very early, I do not think that inbreeding alone was responsible for the fact that relatively more of the females in the later than in the earlier generations of these inbred rats bred at three months of age. In these experiments, when two or more females of a litter were reared as possible breeding stock, the first female that became pregnant was the one taken to continue the line, provided she fulfilled all requirements as to size and vigor. Thus the manner in which breeding females were selected preserved those individuals that tended to breed at an early age, and this tendency to early maturity, if heritable, must have been retained in the stock and intensified to some extent through continued brother and sister matings. Inbreeding, aided by selection, would thus seem to be the factor involved in producing a strain of rats in which the females attained sexual maturity at a relatively early age.

\section{Sterility}

Sterility occurs normally in the Albino, as in other strains of rats, and therefore it might be expected to appear at times in any strain, regardless of whether the animals were inbred or outbred. Crampe ('84) states that of 221 Albino females which he selected for breeding forty-six, or 20.8 per cent, were sterile. 
Out of 124 stock Albino females reared in our own colony during the past three years and intended for breeding purposes thirtytwo, or 28.8 per cent, were completely sterile, while about 10 per cent of those that did breed cast only one or two litters. Unfortunately, no records have been kept that give information regarding the exact proportion of sterile females in the first six generations of the inbred series. The number was relatively very large, and must have included at least one-half of the total number of females that lived to be six months old. Sterility in these females was, for the most part, the result of poor nutrition, and it disappeared as soon as the nutritive conditions were improved. Loeb ('17) has shown that in the guinea-pig "underfeeding prevents maturation of the follicles and thus causes sterility which lasts as long as the effect of the underfeeding is present in the ovary." In the guinea-pig, as in the rat, adequate nutrition reëstablishes normal conditions in the ovary and sterility almost entirely disappears.

In Drosophila, according to Castle et al. ('06), low productiveness (sterility) is' directly transmitted by inheritance and is amenable in selection. In the rat, sterility seems to depend not entirely on genetic factors, but to a marked extent upon conditions, such as malnutrition and disease, that act unfavorably upon reproduction. In the present experiments, by selecting for breeding only the most vigorous individuals (which it seems were also the most fertile), sterility in as far as it may depend on genetic factors would seem to have been practically eliminated from the strain, and it has not reappeared even after twenty-eight generations of brother and sister matings.

Of the 954 inbred females that were used for breeding during the course of these experiments, 653 , or 68.5 per cent, cast four litters each, and many of them, kept for body-weight records, produced several other litters which were not recorded. Of the females that did not cast the required four litters, the great majority died from pneumonia, or were killed because they showed unmistakable evidence of illness. A few of the females stopped breeding after producing one or two litters, although they were apparently in good physical condition and were paired for several 
months with males that were known to be fertile. A postmortem examination of the reproductive organs from several of these semi-sterile females showed, in every instance, an inflamed condition of the ovaries or of the uterus which would render reproduction impossible. Barrenness in these cases was doubtless due to disease and not to any inherent tendency to sterility. A similar diseased condition of the reproductive organs has been found to be responsible for the partial sterility of stock Albinos.

\section{THE CONSTITUTIONAL VIGOR OF INBRED RATS}

The best criterion by which to gauge the so-called 'constitutional vigor' of any animal is undoubtedly its power of reproduction, since that is of the utmost importance for the continuation of the race. There are, however, other important tests for vigor that can be applied, such as the rate and extent of growth, agility, mental alertness, resistance to disease, and ability to live to an advanced age. According to Darwin (78), "the effects of close interbreeding in animals, judging from plants, would be deterioration in general vigor, including fertility, with no necessary loss of excellence of form." This would seem to indicate that, whatever tests were applied, closely inbred animals and plants would show marked inferiority when compared with individuals of the same species that were not inbred. That such a sweeping generalization is not justified is shown by the results of a number of recent inbreeding experiments: the work of Shamel ('05) on tobacco, of Stout ('16) on chicory, and of Hayes and Jones ('17) on tomatoes give no indication that self-fertilization in these plants causes a loss either of vegetative or of reproductive vigor; Gentry's ('05) experiments on swine, and those of Castle et al. ('06) and of Moenkhaus ('11) on Drosophila show that any loss of vigor that might come from inbreeding can be entirely overcome by the proper selection of breeding stock.

The present series of experiments on the rat are the first recorded for any mammal in which brother and sister matings were made continuously for twenty-five successive generations. In the inbreeding experiments with rodents made by Crampe, by Ritzema-Bos, and by von Guaita, matings were made between 
animals related in various degrees, and they were made as often between parent and offspring as between sibs. Ritzema-Bos states: "Bemerkenswert ist namentlich das Result, dass die Paarung zwischen Geschwistern viel schlechtere Erfolge lieferte als die Paarung zwischen Mutter und Sohn, resp. Vater und Tochter." Presumably, therefore, my inbred strain, in which all breeding females came from litters produced by the matings of sibs only, would show an even greater evidence of deterioration in vigor than did the rats inbred by Crampe and by Ritzema-Bos.

Data already given show that these inbred rats were much more fertile than stock rats reared under the same environmental conditions, so it is evident that their reproductive vigor was not impaired. In their ability to withstand disease inbred rats compared favorably with stock rats. The rat scourge, pneumonia, was quite as prevalent among stock animals as among the inbreds and took its toll of lives as frequently and as quickly in one strain as in the other. Parasitic infection was as common in the stock colony as in the inbred, and severe changes in temperature were followed by just as many deaths among stock animals as occurred in the inbred strain. The rat's power of resistance to disease and to unfavorable environmental conditions did not appear to be lessened by inbreeding under the conditions of these experiments.

Records for the growth in body weight of a considerable number of rats belonging in various generations of the two inbred series show the approximate age at which death occurred in all individuals that did not live to the end of the weighing period, which came when the rats were fifteen months old. As similar records were recently obtained for a series of stock animals, it is possible to compare the relative length of life in the two strains and thus to determine whether inbreeding tends to shorten the life of the individuals, as it might be expected to do if it impaired the general vigor of the animals to any extent.

Table 10 shows the mortality at different ages in such of the A series of inbreds as were used for the determination of the effects of inbreeding on the growth in body weight, given in the first paper of this series. For convenience the data were arranged in generation groups: the last group includes the findings through 
the twenty-third generation only, as the weight records for animals belonging in the twenty-fourth and in the twenty-fifth generations are not yet completed. As all of the animals reached the age of three months, the first mortality record given is that for animals at six months of age.

On examining the mortality data for the males, as given in table 10, it is found that comparatively few of the animals in any generation group died before the age of six months, and that over 50 per cent of them lived to be more than one year old. A comparison of the corresponding records for the various generation groups shows unmistakably that the animals belonging to

TABLE 10

Showing the mortality at different ages in a group of 236 males and 179 females belonging in the seventh to the twenty-third generations of the $A$ series of inbred rats

\begin{tabular}{|c|c|c|c|c|c|c|c|c|c|c|}
\hline \multirow{2}{*}{$\begin{array}{c}\text { GENER- } \\
\text { ATION } \\
\text { GROUPS }\end{array}$} & \multirow{2}{*}{$\begin{array}{c}\text { NUM- } \\
\text { BER OF } \\
\text { MALES }\end{array}$} & \multicolumn{4}{|c|}{$\begin{array}{l}\text { PER CENT MALES LIVING AT } \\
\text { VARIOUS AGES }\end{array}$} & \multirow{2}{*}{$\begin{array}{l}\text { NUMEER } \\
\text { OF } \\
\text { FTMALES }\end{array}$} & \multicolumn{4}{|c|}{$\begin{array}{c}\text { PER CENT FEMALIES LIVING AT } \\
\text { VARIOUS AGES }\end{array}$} \\
\hline & & $6 \mathrm{mos}$. & $9 \mathrm{mos}$. & $12 \mathrm{mos}$. & $15 \mathrm{mos}$. & & $6 \mathrm{mos}$. & $9 \mathrm{mos}$. & $12 \mathrm{mos}$. & $15 \mathrm{mos}$ \\
\hline $7-10$ & 35 & 91.4 & 71.4 & 54.3 & 45.7 & 28 & 92.8 & 67.8 & 25.0 & 10.7 \\
\hline $11-14$ & 52 & 90.3 & 71.1 & 57.7 & 38.4 & 37 & 97.3 & 83.8 & 56.7 & 35.1 \\
\hline $15-18$ & 60 & 100.0 & 75.0 & 53.3 & 26.6 & 47 & 97.8 & 72.3 & 59.5 & 29.8 \\
\hline $19-23$ & 89 & 98.8 & 88.7 & 73.0 & 46.0 & 67 & 98.5 & 82.1 & 67.1 & 46.2 \\
\hline $7-23$ & 236 & 96.2 & 78.8 & 61.9 & 39.4 & 179 & 97.2 & 77.6 & 56.4 & 34.1 \\
\hline
\end{tabular}

the later generations tended to be longer lived than did those in the earlier generations.

The mortality data for the females of the A series are much like those for the males, the most noticeable difference being found in the records for the first generation group where only 10 per cent of the females lived to be fifteen months of age. Taking the animals of the $A$ series as a whole, about 4 per cent of them died before they reached the age of six months; 20 per cent did not live to the age of nine months; 50 per cent were dead at the end of one year, and only about 35 per cent lived to be fifteen months old.

Mortality data for individuals belonging to various generation groups of the B series are shown in table 11 . 
In the earlier generations of the $\mathrm{B}$ series the mortality in both males and females was considerably greater than that in the animals belonging to the A series: only 5 per cent of the males lived to be fifteen months old, while not a single female reached this age. For the later generation groups the data for the B series were very similar to those for the A series. As a whole, however, the animals in the $A$ series lived longer than did those in the $\mathrm{B}$ series.

The data given in table 10 and in table 11 have been combined in table 12. This table shows also mortality data for 377 stock albino rats reared in The Wistar Institute animal colony during the past three years. Included in the latter series are the

TABLE 11

Showing the mortality at different ages in a group of 151 males and 231 femaites belonging in the seventh to the twonty-thurd generatrons of the $B$ series of inbred rats

\begin{tabular}{|c|c|c|c|c|c|c|c|c|c|c|}
\hline \multirow{2}{*}{$\begin{array}{l}\text { GENER- } \\
\text { ATTON } \\
\text { GROUPS }\end{array}$} & \multirow{2}{*}{$\begin{array}{c}\text { NUMA- } \\
\text { BER OF } \\
\text { MALES }\end{array}$} & \multicolumn{4}{|c|}{$\begin{array}{c}\text { PER CENT MALES LIVING AT } \\
\text { VARTOUS AGES }\end{array}$} & \multirow{2}{*}{$\begin{array}{c}\text { NUMBER } \\
\text { OF } \\
\text { FEMALES }\end{array}$} & \multicolumn{4}{|c|}{$\begin{array}{l}\text { PER CENT FFMALES LIVING AT } \\
\text { YARIOUS AGES }\end{array}$} \\
\hline & & $6 \mathrm{mos}$ & $9 \mathrm{mos}$ & $12 \mathrm{mos}$ & $15 \mathrm{mos}$ & & 6 mos. & $9 \mathrm{mos}$. & $12 \mathrm{mos}$. & $15 \mathrm{mos}$ \\
\hline $7-10$ & 18 & 94.4 & 50.0 & 38.8 & 5.5 & 34 & 79.4 & 23.5 & 17.6 & \\
\hline $11-14$ & 30 & 86.6 & 70.0 & 26.6 & 6.6 & 43 & 90.7 & 65.1 & 34.9 & 16.2 \\
\hline $15-18$ & 43 & 100.0 & 69.8 & 51.1 & 27.9 & 64 & 96.9 & 76.5 & 54.6 & 26.5 \\
\hline $19-23$ & 60 & 100.0 & 93.3 & 76.6 & 56.6 & 90 & 100.0 & 86.6 & 77.7 & 53.3 \\
\hline $7-23$ & 151 & 97.2 & 76.8 & 54.9 & 32.4 & 231 & 94.3 & 70.6 & 54.5 & 31.1 \\
\hline
\end{tabular}

records, elsewhere published (King ,'15), for fifty males and for fifty females of selected stock that were reared as controls for the. inbred strain.

The mortality data for the inbred rats, given in table 12, show that close inbreeding did not tend to shorten, but to lengthen the span of life in both males and females: 50 per cent of the animals belonging to the last group lived to be fifteen months of age, while in none of the other groups did even 30 per cent of the individuals attain this age. It is probable that the relatively high death rate in the animals of the earlier generations was due to the fact that the rats had not regained the vigor that was so greatly impaired in their ancestors by malnutrition. 
Donaldson ('06) has assumed that the span of life in man is thirty times that of the rat, and therefore that a rat of three years corresponds to a man of ninety years. Considering the relatively small proportion of men that live to be nonagenarians, one would not expect to find many rats in any colony living to three years of age, yet under the equitable climate of California, Slonaker ('12) succeeded in keeping two of a series of sixteen albino rats beyond this age, and one of them lived for forty-five months, or the equivalent of one hundred and twelve years of human life. At various times during the past five years a number

TABLE 12

Showing the mortality at different ages in a group of 387 males and 410 females belonging in the seventh to the twenty-third generations of the two inbred series (a combination of the data in table 10 and in table 11). Data are also shown for the mortality in a serves of stock albino rats comprising 199 males and 178 females

\begin{tabular}{|c|c|c|c|c|c|c|c|c|c|c|}
\hline \multirow{2}{*}{$\begin{array}{l}\text { GENERATTON } \\
\text { GROUPS }\end{array}$} & \multirow{2}{*}{$\mid \begin{array}{c}\text { NUM- } \\
\text { BER OF } \\
\text { GROUPS }\end{array}$} & \multicolumn{4}{|c|}{$\begin{array}{l}\text { PER CENT MALES LIVING AT } \\
\text { VARIOUS AGES }\end{array}$} & \multirow{2}{*}{$\mid \begin{array}{c}\text { NUM- } \\
\text { BER OF } \\
\text { TE- } \\
\text { MARAS }\end{array}$} & \multicolumn{4}{|c|}{$\begin{array}{l}\text { PER CENT FWMALES LIVING AT } \\
\text { VARIOUS AGES }\end{array}$} \\
\hline & & 6 mos. & 9 mos. & $12 \mathrm{mos}$ & $15 \mathrm{mos}$. & & 6 mos. & $9 \mathrm{mos}$. & $12 \mathrm{mos}$. & $15 \mathrm{mos}$ \\
\hline $7-10$ & 53 & 92.4 & 64.1 & 49.0 & 32.0 & 62 & 85.4 & 43.5 & 20.9 & 4.8 \\
\hline $11-14$ & 82 & 89.0 & 70.7 & 47.1 & 26.8 & 80 & 93.7 & 73.7 & 45.0 & 25.0 \\
\hline $15-18$ & 103 & 100.0 & 72.8 & 52.4 & 27.1 & 111 & 97.3 & 74.8 & 56.7 & 27.9 \\
\hline $19-23$ & 149 & 99.3 & 90.6 & 74.5 & 50.3 & 157 & 99.3 & 84.9 & 73.3 & 50.3 \\
\hline $7-23$ & 387 & 96.3 & 78.0 & 59.2 & 36.7 & 410 & 95.6 & 73.6 & 55.3 & 32.0 \\
\hline tock series. & 199 & 98.9 & 85.9 & 63.8 & 28.1 & 178 & 95.5 & 87.6 & 70.2 & 37.6 \\
\hline
\end{tabular}

of inbred and of stock Albinos were kept in our colony in good physical condition until they were about two years old. We have never attempted to keep any rats beyond this age.

Osborne, Mendel and Ferry ('17) state that out of ninety-one albino rats kept under ordinary laboratory conditions during their entire lifetime, "17 (19 per cent) died under one year of age; 48 ( 53 per cent) died between one and two years of age; and 26 (29 per cent) lived more than two years, the oldest one reaching an age of nearly 34 months. From these figures it is evident that less than a third of the rats in our colony may be expected to live to be more than two years old." In another paper these 
authors ('15) state: "Fully half of our stock rats have died before the age of 600 days." Unfortunately, the mortality data given by Osborne, et al. are not in a form which makes it possible to compare them directly with the records for these inbred rats. It would seem, however, from the results as given, that their animals tended to live longer than the rats in my inbred strain. The mortality data for the series of stock Albinos, given in table 12 , can be directly compared with those for the inbred rats given in the same table, since both series of animals were reared under similar environmental conditions and the records were taken at the same age intervals. Relatively more of the stock than of the inbred males were living at six, nine, and twelve months of age, but only 28 per cent of the stock males lived to be fifteen months old, while 37 per cent of the inbred males attained this age. The records for the female groups show that relatively as many inbred as stock females lived to the age of six months, but that more of the stock than of the inbreds were living at nine, twelve, and fifteen months of age. Taken as a whole, therefore, longevity in the inbred strain seemed to be somewhat less than that in the stock controls.

Some of the inbreeding data for animals which Darwin (75) collected were so at variance with his own results on plants that he was forced to admit that; "manifest evil does not usually follow from pairing the nearest relations for two, three, or even four generations." In a long-continued series of inbreeding experiments, therefore, the deleterious effects of inbreeding would supposedly be more accentuated in the later than in the earlier generations. A comparison between the mortality records for stock animals and those for the inbred group comprising the animals in the nineteenth to the twenty-third generation should show the effects of inbreeding on longevity much better than the comparison between the groups as previously made. Such a procedure is the more justifiable, perhaps, because these two groups of animals were reared in the colony simultaneously. While in the two male groups only about 1 per cent of the animals failed to reach the age of six months, relatively more of the inbred than of the stock males were living at all other age periods noted: 
the final records for the two groups show a difference of 22.2 per cent in favor of the inbred animals. In the female groups the span of life in the inbreds also tended to be longer than that in the controls, but the difference was not quite as marked as in the case of the males: the final records show a difference of only 12.7 per: cent.

It appears, from the above comparison of data for stock and inbred rats, that continued inbreeding, under favorable environmental conditions and with the aid of selection, cannot only lessen the tendency to early death caused by malnutrition, but that it can extend the average span of life in the rat considerably beyond that found in the stock controls. Constitutional vigor, as judged by the longevity of the individuals, is therefore not invariably lessened by continued inbreeding.

In table 10 and in table 11 it will be noted that the mortality data for the first generation group indicate that the span of life in the females, particularly in the $B$ series, was much shorter than that in the males. The reason for this 'selective mortality' is not clear, although it may be that the females were not able to throw off the effects of malnutrition quite as readily as were the males. In both inbred series, after the tenth generation, the mortality in the females at any age period was practically the same as that in the corresponding group of males. Data given in table 12 show that stock females tended to live longer than stock males: a reversed relation seemed to hold for the inbred rats. Taking the inbred colony as a whole, I am inclined to the opinion that the females, as a rule, tend to live longer than do the males. More males than females usually die as the result of a sudden, sharp change in temperature, and the impression one gets from working daily with the animals is that the males are far more susceptible to pneumonia than are the females, and that they are sooner attacked by various parasitic pests, such as lice and earmites. White ('14) states that in India the bubonic plague is a more fatal disease to male than to female rats, thus indicating that the female is stronger, constitutionally, than the male. These results are in accord with the findings for the human race: census reports and various statistical tables that have been com- 
piled show, as does the investigation of Pearson et al. ('03), that the duration of life in women is longer than it is in men and that women are the less susceptible to disease at all ages.

The various physical defects, so prevalent among Crampe's ('83) inbred rats, were all found among my inbred rats at the beginning of these experiments, but they were due to malnutrition, not to inbreeding, since they entirely disappeared when the animals received proper food. Among the thousands of inbred animals that were reared during the past five years some few, not to exceed a dozen in all, lacked one or both eyeballs. This defect has also appeared, at times, in stock animals. On the average, one in every 10,000 rats born in the stock colony is tailless. This abnormality, as Conrow ('15, '17) has shown, involves the skeletal structure in the entire pelvic region. The inbred colony has contained only one tailless individual as yet. Unfortunately, this lat was destroyed by the mother soon after birth, so it was not carefully examined. Neither of these defects appears to be heritable, and neither can be due to inbreeding, since each has appeared also in a stock that is outbred. No other abnormalities of any kind have appeared in the animals of the inbred strain up to the present time when the individuals of the twenty-eighth generation are approaching maturity. The findings in this series of experiments, therefore, do not give support to Ritzema-Bos' contention that inbreeding tends to cause "eine grössere Prädisposition für Krankheiten und das Entstehen von Missbildungen." When a considerable number of animals belonging to any series exhibits various kinds of malformations, it is safe to assume that either environmental and nutritive conditions are unfavorable to normal development, as in the early part of the present series of experiments, or that there is an inherent weakness in the stock used that is brought out and accentuated by random inbreeding, as seemed to be the case with Crampe's rats.

No data are available for a direct comparison between stock and inbred rats as regards their relative activity at different ages, but several series of experiments have been made in different psychological laboratories in which the behavior of rats from this inbred strain was compared with that of stock controls. 
In the inbred rats of the earlier generations the brain and spinal cord were decidedly below the normal weight of these organs in stock animals of like age and body weight. "From the fourth to the tenth generation the relative brain weight remained, on the average, constant at six and one-half per cent less than that of the normal control rats" (Basset, '14). The habit formation in a number of rats that belonged in the sixth and in the seventh inbred generations was tested at Johns Hopkins University by Basset (14), who found that these animals were inferior to stock rats in their ability to form habits, and that they show less retention of a habit, and were longer in relearning it, than were the controls.

Inbred rats belonging in the twelfth and in the fourteenth generations were sent to Harvard University where Mrs. Yerkes ('16) studied their behavior and compared it with that of stock albino rats obtained from The Wistar Institute colony and from a different source of supply. The general conclusion reached by Mrs. Yerkes was that "inbred rats learned a trifle more slowly than the stock rats, both in the maze and in the discrimination experiments, but that they carried discrimination of lightness and darkness further, and showed the most pronounced difference only in their greater timidity and instability of behavior."

Temperamental differences between stock Albinos and inbreds of the fourteenth and the fifteenth generations were investigated at Harvard by Utsurikawa ('17). The results obtained showed that inbred rats were less active and more savage than the outbred rats, and that they responded more quickly and in greater amount to momentary auditory stimulation than did outbred rats. The two strains were found to differ also in "restlessness or continuity of response." Inbred rats showed the greatest restlessness" in case of momentary and repeated auditory stimulation and less in case of continued stimulation, whereas for the outbred animals the reverse is true." These temperamental differences between inbred and stock rats would seem to indicate that inbred rats are more 'high strung' nervously than are outbred rats. Nervousness is a trait manifested by many thoroughbred animals, and it is particularly characteristic of the racehorse. 
The nervousness of the horse is undoubtedly the result of continued selection, since breeders consider that an animal must have this trait highly developed if it is to be a success on the track. If nervousness is a trait that is transmitted by inheritance and amenable to selection it is probably also a trait that would tend to be intensified by close inbreeding, ard therefore it might be expected that rats closely inbred for many generations would be somewhat more nervous than outbred stock controls, as Utsurikawa found to be the case.

When the last two series of investigations were completed the animals used were sent to The Wistar Institute where they were killed and carefully examined by Dr. Hatai. It was found, as Mrs. Yerkes states, that the inbred rats had a somewhat greater body length and body weight than the stock rats, and that they showed a brain weight in relation to body length and body weight that was only from 0.002 per cent to 0.006 per cent less than that of stock rats. Since the inbred rats of the sixth and of the seventh generations had a brain weight about six and one-half per cent less than the normal (Basset, '14), it would appear, from Mrs. Yerkes' findings, that somewhere between the seventh and the twelfth generations the animals entirely recovered from the effects of malnutrition and became normal again with respect to the relative weight of the central nervous system. They have remained normal in this regard up to the present time, as autopsies made at various periods on animals of the later generations have shown.

With the return of the central nervous system to its normal weight relations, the inbred rats must have regained much of their lost mental vigor, since in behavior tests animals of the fourteenth generation were found to be inferior to stock animals only in that they were slower and less active. The lesser activity of the inbred rats Mrs. Yerkes ascribes to "a greater timidity and a greater susceptibility to environmental conditions." Savageness, wildness, and timidity are heritable behavior complexes, according to R. Yerkes ('13), and since no attempt was made in the course of these experiments to eliminate these traits by selection, it is not surprising that they were manifested in a somewhat intensified form after many generations of close inbreeding. 


\section{DISCUSSION}

Wherever inbreeding has been practiced it has usually been accused of producing anything and everything undesirable that has appeared in the offspring. The following quotation from Mitchell ('65) is quite typical of the belief that prevailed among zoologists, as well as among the laity, until the past decade, regarding the effects of consanguineous marriages:

Consanguinity in parentage tends to injure the offspring. This injury assumes various forms. It may show itself in diminished viability at birth; in feeble constitutions, exposing them to increased risks from the invasion of strumous disease in after life; in bodily defects and malformations; in deprivation or impairment of the senses, especially those of hearing and sight; and, more frequently than in any other way, in errors and disturbances of the nervous system, as in epilepsy, chorea, paralysis, imbecility, idiocy, and moral and intellectual insanity. Sterility or impaired reproductiveness is another result of consanguinity in marriage, but not one of such frequent occurrance as has been thought.

Stock breeders, also, have been imbued with the idea that inbreeding is always inimical to constitutional vigor and that it leads to sterility. For these reasons most of them have opposed the mating of animals related even in a remote degree. During the past few years it has been shown by a number of carefully controlled experiments that inbreeding does not necessarily produce the evil effects that have been attributed to it, and that the results obtained in any inbreeding experiment depend, primarily, on the soundness of the stock that is inbred; secondarily, on the selection of animals for breeding purposes, and, finally, on the environmental conditions under which the animals live. Haphazard inbreeding of inferior stock under unfavorable environmental conditions has produced many of the failures for which inbreeding alone has been held responsible.

Since the experiments of Crampe ('83), of Ritzema-Bos ('93, '94), and of von Guiata ('98, '00) have furnished the classic examples of the dire effects of inbreeding on rodents, it may be well to examine these experiments in some detail to see whether the unfavorable results obtained cannot be traced to some cause other than inbreeding per se. 
Crampe's inbreeding experiments were begun, in 1873, with an Albino female and a white and gray male. From the mating of these rats he obtained the litter of five young which formed the basis of his breeding stock. These animals were inbred, in various degree of relationship, for seventeen successive generations. Crampe states that many of the animals were sterile and that others lost their reproductive instincts at the end of the first year. Various kinds of malformations appeared; the animals were seemingly too weak to resist disease of any kind, and they died at a relatively early age. The weakness of these rats and their susceptibility to disease, as well as the high degree of sterility among them, all point to the probability, as Ritzema-Bos suggests, that Crampe started his experiments with animals taken from a defective stock. Since results similar to Crampe's were obtained in the early part of my own experiments, I am inclined to the opinion that inadequate nourishment was a factor that was responsible, in great part, for his failure to maintain the stock in good physical condition.

Ritzema-Bos started his investigation in 1886 with a litter of twelve rats that was obtained from the mating of an Albino female and a wild Norway male. These rats were inbred, in various ways, for six years, during which time, Ritzema-Bos states, "about thirty generations were obtained." There is evidently some inaccuracy in this latter statement. The female albino rat does not cast her first litter until she is about three months old; wild rats do not breed, as a rule, before they are four or five months old. Assuming that all of the females used in RitzemaBos' experiments bred at the earliest possible age, i.e., three months, only four generations could possibly be produced in a year: this would give al maximum of twenty-four generations at the end of six years. In my own experiments an average of about three and one-half generations a year were obtained.

Ritzema-Bos gives data showing the average size of the litters and the number of infertile matings during the various years in which the work was in progress. These data have been reproduced in table 13 . 
During the first three years, as table 13 shows, there was little diminution in the average size of the litters produced. In the three following years, however, litter size decreased considerably, and at the end of the investigation the litters averaged less than one-half the size of those obtained in the beginning. These results certainly justify Ritzema-Bos' conclusion that: "Die fortgesetze Zucht in engster Verwandtschaft vermindert das Fortpflanzungsvermögen, kann sogar schliesslich vollkommene Unfruchtbarkeit verursachen." Lloyd ('12) has suggested that the deterioration in Ritzema-Bos' stock might have been due to overcrowding, since many varieties of rats will not breed in close confinement.

TABLE 13

Showing Ritzema-Bos' data for the average size of the litters and for infertle matings in a series of inbred rats

\begin{tabular}{c|c|c}
\hline Y IRAR & $\begin{array}{c}\text { AVERAGE NUMBER OF YOUNG } \\
\text { PER LITTER }\end{array}$ & PER CDNT INFERTILE MATINGs \\
\hline 1887 & 7.5 & 0.00 \\
1888 & 7.1 & 2.63 \\
1889 & 7.1 & 5.55 \\
1890 & 6.5 & 17.39 \\
1891 & 4.2 & 50.00 \\
1892 & 3.2 & 41.18 \\
\hline
\end{tabular}

Von Guaita obtained a number of white mice from a strain that had been inbred by August Weismann for twenty-nine generations. How these mice were inbred I do not know, since I have not been able to find any account of the details of this experiment. Von Guaita crossed these white mice with Japanese waltzing mice, and then inbred their descendants for five generations. The data regarding the average size of the litters obtained in these two sets of investigations are shown in table 14.

Weismann's data, given in table 14, show that the average size of the litters decreased directly as the inbreeding advanced, and so appear to indicate that inbreeding lessened the fertility of the mice. In this experiment there seems to have been a very great difference in the number of litters that were produced in the various generations. In the first two generations there was an aver- 
age of about twenty-two litters to the generation: in the last nine generations the average was only about three litters to a generation. Such a small number of litters as that produced in the later generations of this series does not afford an opportunity for a careful selection of breeding stock, neither does it furnish sufficient data to make the results of statistical value.

In the successive generations of mice bred by von Guaita there was, to quote Davenport ('00): "a reduction in fertility of about 30 per cent, and this is probably due to close inbreeding." In order to make this deduction from von Guaita's data, however, it

TABLE 14

Showing the number and average size of the litters in twenty-nine generations of white mice inbred by August Wersmann, and in seven generations of hybrid mice inbred by von Guaita

\begin{tabular}{|c|c|c|c|}
\hline & GENHRATIONS & $\begin{array}{l}\text { NCMBER OF } \\
\text { LITTERS }\end{array}$ & $\begin{array}{c}\text { AVERAGK } \\
\text { NUMBER OF } \\
\text { YOUNG PER } \\
\text { LITPER }\end{array}$ \\
\hline \multirow{3}{*}{ Weismann's data for white mice..... } & $1-10$ & 219 & 6.1 \\
\hline & $11-20$ & 62 & 5.6 \\
\hline & $21-29$ & 29 & 4.2 \\
\hline \multirow{6}{*}{ Von Guaita's data for hybrid mice.. } & 1 & 7 & 4.4 \\
\hline & 2 & 15 & 3.0 \\
\hline & 3 & 25 & 3.8 \\
\hline & 4 & 31 & 4.3 \\
\hline & 5 & 30 & 3.2 \\
\hline & 6 & 11 & 2.3 \\
\hline
\end{tabular}

is necessary to combine the records for three generations, as Davenport did. If the records for the various generations are considered separately, or grouped by twos, there is not the steady decrease in fertility with advancing inbreeding that Davenport's grouping of the data implies. Taking the data for the first two generations together, the average size of the litters was 3.7 ; for the next two generations there was an average of 4.0 young per litter; in the final group the litters averaged 2.7 young. Since the crossing of varieties is supposed to increase vigor and fecundity it seems strange that the $F_{1}$ and the $F_{2}$ litters in this series should contain a smaller average number of young than is found in the 
normal litter of either of the varieties that were crossed (five to six young per litter). Since crossing did not restore the normal fertility of the individuals, it would seem as if there must have been a strong tendency to sterility in each of the strains crossed. If such were the case, continued inbreeding, apparently without selection, would bring out this latent character and intensify it.

It seems rather remarkable that, of the many writers who have cited the results of the above series of experiments as proof that close inbreeding lessens fertility, not one, to my knowledge, has emphasized the fact that all of these experiments were made with hybrids and not with a pure strain. Hybridization in itself, as many investigators have noted, often produces a most marked effect on fertility. Some hybrids are equal, or even superior to the parent stock in fertility others are completely sterile; and among the hybrid offspring from various crosses all grades of productiveness from normal to complete sterility have been found. When hybridization increases fertility, its most marked effect is usually found in the animals of the $F_{1}$ and $F_{2}$ generations, and in later generations productiveness, as a rule, tends to decrease.

In connection with another problem, I have for several years been breeding the $F_{1}$ hybrids between the wild Norway and the albino rat, and I have also inbred various strains of 'extracted' rats, brother and sister, for several generations. Careful records have been kept of the litter production in all of these strains. While the great majority of the $F_{1}$ hybrid females are fertile, at least 25 per cent of the $\mathrm{F}_{2}$ females are completely sterile, and about 10 per cent of those that do breed have only one or two litters. None of the 'extracted' strains that I have studied have even been as fertile as the inbred Albinos. The increase of sterility and the diminution in litter size with continued inbreeding has been very marked in some of these strains, but this lessened productiveness has been due, I believe, to hybridization, and it has not been influenced by inbreeding save in as far as inbreeding has intensified the tendencies which acted unfavorably upon productiveness. By rigid selection of only the most ferrtile individuals for breeding, from a large potential breeding stock, it might be possible to eliminate from the 'extracted' strains of rats 
the tendency to sterility that is seemingly caused by hybridization. Such a selection was not attempted, apparently, in any of the series of experiments cited above, nor was it done in my own work with hybrid stock. The experiments of Crampe, of Ritzema-Bos, and of von Guaita show unquestionably that fertility in hybrid rats is diminished by random inbreeding, but they cannot legitimately be used to give evidence regarding the effects of inbreeding on the fertility of a pure race.

Other series of inbreeding experiments made on pure strains of rodents show that inbreeding does not necessarily lead to a marked decrease in fertility. Neither Schultze ('03) nor Copeman and Parson ('09) found inbred mice less productive than the outbred strain; Castle ('16) did not find any great decrease in fertility in various races of rats inbred for seventeen generations. In the inbreeding experiment with guinea-pigs that has been carried on for several years at the Bureau of Animal Industry in Washington, there is, to quote Popenoe ('17): "no general deterioration. While a few strains have run out, others are nearly as vigorous as are the control families."

Results comparable to the above have been obtained with other animals. It is well known that inbreeding has been used extensively, and with very favorable results, in the building up of various strains of thoroughbred horses and cattle (Wriedt, '16), and the productiveness of these strains has not been greatly lessened. In the extensive series of inbreeding experiments with Drosophila, made by Castle et al. ('06), it was found that "inbreeding probably reduces very slightly the productiveness of Drosophila, but the productiveness may be fully maintained under constant inbreeding (brother and sister) if selection is made from the more productive families. . . . . Selection has a much greater influence on fertility than inbreeding, so that selection from the most productive pairs is able to more than offset the effects of inbreeding." The effectiveness of selection in increasing the fertility within an inbred strain is shown with great clearness in Moenkhaus' ('11) experiments with Drosophila. Moenkhaus was able to establish two distinct strains, one of high and one of low fecundity, by selecting, from among the variable 
offspring of the fourteenth generation of a closely inbred race, pairs of individuals showing very different degrees of productiveness and then inbreeding their descendants. Moenkhaus continued some of his lines for seventy-five generations and found that close inbreeding (brother and sister) was not deleterious either to fertility or to vigor. Hyde ('14) has found also that in certain strains of Drosophila sterility is an inherited character that is not influenced by inbreeding, and that "selection is an effective agent in controlling it."

In the present series of inbreeding experiments on the rat, the productiveness of the strain was decreased by malnutrition during the early generations, but normal fertility was restored as soon as the animals were adequately nourished. In later generations the fertility in the inbred animals was greater than that in the series of stock controls reared under similar environmental conditions. Thus even after a high degree of sterility had been introduced into the strain it was not retained in spite of the fact that close inbreeding was continued. In the later generations any tendency to sterility that appeared was evidently suppressed by selection. In the rat, as in Drosophila, selection seems a more potent factor for good than inbreeding is for evil.

During the past few years it has been shown, by a series of brilliant experiments, that characters tend to be inherited in groups and that this grouping depends upon the fact that the genetic factors involved are not segregated independently in gametogenesis, but tend to be linked together (Morgan et al., '15). In these experiments with the rat it has been found that animals that are large and vigorous when young tend to mature early, to be very productive, and to live to an advanced age. While all of these characters are influenced to a considerable degree by environmental conditions, it is evident that they must all depend to some extent upon heritable genes, since they are transmitted from generation to generation. A selection of breeding animals on the basis of size and early maturity has meant also selection for high fecundity and for characters that represent, superior vigor of constitution, it would seem as if the genetic factors involved must tend to be inherited together, although they are probably not linked as are many of the genes in Drosophila. 
Wentworth's ('13) experiments with Drosophila indicate that the supposed weaknesses from inbreeding are due to "the mere segregation of factors for lower vigor." Assuming that a similar segregation of these factors occurred in the inbred rats during the early generations, individuals containing the factors for 'lower vigor' were evidently eliminated by the selective action of malnutrition, and only those animals containing dominant genes for 'high vigor' were able to survive and to perpetuate their kind. Neither inbreeding nor selection is creative in its action. Selection can act on fertility only by preserving those individuals that contain genes for characters favorable to reproduction; inbreeding conserves these characters, and, to a certain extent, intensifies them. The action of both selection and inbreeding can be nullified by unfavorable conditions of environment or of nutrition which may produce a rapid deterioration in the fertility of any stock, regardless of the way in which the animals are bred.

It was shown by the work of Darwin ('78), as well as by a number of more recent experiments (Shull, '10; East and Hayes, '12; Hayes and Jones, '17), that crosses between different varieties of plants often produce hybrids that possess greater reproductive vigor than either parent stock. This result is due, according to East and Hayes ('12), to "the stimulation of vigor through heterozygosis." Inbreeding, these authors state, "tends to isolate homozygous strains which lack the physiological vigor due to heterozygosity. Decrease in vigor due to inbreeding lessens with decrease in heterozygosity and vanishes with the isolation of a completely homozygous strain." If the latter is a good strain, because of its gametic constitutional and natural inherent vigor, it is "ready to stand up forever under constant inbreeding."

The results obtained in these inbreeding experiments with the rat accord with the theory of East and Hayes to some extent. The effects of inbreeding on the fertility and on the vigor of the rats were obscured in the early generations by the action of malnutrition, but it would appear that the animals lost very little of their constitutional vigor during this time, since adequate nutrition soon restored the normal productiveness of the strain and its general vigor as well. Apparently at about the tenth generation, 
the inbred rats became sufficiently homozygous for vigor to become fairly constant. Beyond the point, as the data show, there was little variation in the fertility or in the longevity of the animals up to the twenty-fifth generation. Selection and favorable environment kept the strain at a point of high productiveness, but, under the conditions of the experiment, they did not increase vigor beyond the stage which was reached at the tenth generation. As already stated, no attempt was made in the course of these experiments to influence fertility by selecting breeding animals from large or from small litters. Whether selection can act in the rat, as it does in Drosophila, and produce strains of high and of low productiveness within a line that has been inbred for many generations is a problem for the future. As the strain has been very fertile for many generations it seems very improbable that any sudden loss in fertility will occur in the future, unless sterility appears as a mutation which cannot be eliminated by selection.

While corresponding records for the two inbred series $(A, B)$ are in close agreement, there are, nevertheless, differences between the series that have persisted from the very beginning. Female A, one of the two females with which the experiment were started, showed a relatively high degree of fertility since she gave birth to five litters, containing thirty-five young, before she was killed at the age of one year: female $B$, a sister of female $A$, cast only one litter of five young, although she was paired continuously for several months and appeared to be in good physical condition. The two litter brothers with which these females were paired showed no marked differences in size or in vigor. The rats of the $\mathrm{A}$ series (which were descended from female $\mathrm{A}$ ) were, as the records show, somewhat more fertile than the rats of the B series (the descendants of female B), and they also tended to mature earlier and to live longer. The differences found were not very marked in any case, and they might well be ignored were it not for the fact that in all of the characters noted the animals of the A series were superior to those of B series. Environment cannot be held accountable for these differences, since the two series of inbreds were kept constantly under similar conditions of 
light, of temperature, and of nutrition. Although the two series were descended from the same ancestral stock, apparently there was an inherent difference in the gametic constitution of the two pairs of rats with which the experiment was started, which persisted from generation to generation and produced the effects noted.

While the inbred strain of rats that has been developed in the course of these experiments is seemingly superior to the average run of stock Albinos in body size, in fertility, and in longevity, I do not claim that this superiority is due solely to the fact that the animals were inbred, neither do I wish to assert that, in general, inbreeding is better than outbreeding for building up and for maintaining the general vigor of a race. The two forms of breeding are not mutually exclusive: each has its merits, and the one should supplement the other to bring out the best in any stock. The favorable results that have been obtained in these experiments have been achieved through the constant selection of only the best animals from a larger number available for breeding purposes and by keeping the environmental conditions as uniform and as favorable as it was possible to make them. These experiments have fully demonstrated, I think, that even in mammals the closest form of inbreeding possible, i.e., the mating of brother and sister from the same litter, is not necessarily injurious either to the fertility or to the constitutional vigor of a race even when continued for many generations. Success or failure in inbreeding experiments depends chiefly, it would seem, on the character of the stock that is inbred, on the manner in which the breeding animals are selected, and on the environmental conditions under which the animals are reared. There is no warrant, therefore, either in theory or in fact, for the dogmatic assertion of Kraemer ('13) that: "continued inbreeding must always result in weakened constitution, through its own influence."

\section{SUMMARY}

1. The present paper gives data showing the fertility, the time of puberty, and the longevity in two series of albino rats $(A, B)$ that were.inbred, litter brother and sister, for twenty-five generations. 
2. Data given for the A series of inbreds comprise 1752 litters containing 13,116 individuals, or an average of 7.5 young per litter (table 1); records for the B series of inbreds include 1656 litters having a total of 12,336 members, or an average of 7.4 young per litter (table 2 ). The two series combined comprise a total of 3408 litters which contained 25,452 individuals. For the entire strain the average size of the litter was 7.5 young.

3. In any litter series of albino rats, whether the animals are inbred or outbred, the first litter cast is the smallest of the series, as a rule; the second litter is the largest; while the third and fourth litters are about the same size and a little smaller than the second litter.

4. The size of any litter cast depends chiefly on the age and physical condition of the female, and is not affected by the relatedness or the unrelatedness of the parents.

5. A comparison of the data for the inbred strain with data for litter size obtained from a series of stock Albinos reared under the same environmental conditions as the inbred strain shows that each litter of the stock series was relatively smaller than the corresponding litter in the inbred group. For the entire series of 424 stock litters the average size was 6.7 young per litter. This average is 0.8 less than the average for litter size in the inbred strain (table 7 ).

6. In the A series of inbreds the range in litter size was from one to seventeen; in the B series it was from two to fifteen. In both series the most frequent litter size was seven (table 8).

7. In the early generations of these inbred rats malnutrition greatly delayed the time of puberty in the animals. In the later generations, under favorable nutritive conditions, the animals bred at a relatively early age.

8. While the records give no definite information regarding the number of sterile animals in the inbred strain, they show clearly that inbreeding did not decrease the productiveness of the animals. Of the 954 females that were used for breeding, 653 , or 68.5 per cent cast the required number of four litters. Where partial sterility occurred in apparently healthy females it was found to be due to a diseased condition of the reproductive organs. 
9. The constitutional vigor of these rats was apparently not impaired to any extent by inbreeding. Only two kinds of malformations were found in the animals of the inbred strain after food conditions were improved: one individual was born tailless and about a dozen individuals lacked one or both eyeballs. Both of these defects occur in outbred stock Albinos and neither appears to be heritable.

10. Under the conditions of these experiments the span of life in both the males and females in each of the inbred series was increased. The records show that inbred males tended to live longer than did inbred females: a reversed relation was found in the animals of the control series. In the inbred colony as a whole, the females seemed to be longer lived than the males and they were less susceptible to disease at all ages.

11. According to the behavior tests that were made, inbred Albinos are slower, less active, more timid and nervous, and somewhat more savage than stock Albinos that are outbred.

12. High fecundity, early sexual maturity, and vigorous growth are characters that seemed to be inherited as a group in the inbred strain of rats. It seems probable that the genetic factors on which these characters depend do not segregate independently, but tend to combine in gametogenesis.

13. The animals of the $A$ series were slightly more fertile than the animals of the $B$ series, they attained sexual maturity earlier, as a rule, and they lived longer. These differences probably depended in some way on a dissimilarity in the gametic constitution of the two pairs of individuals with which the experiments were started.

14. The results obtained in these experiments do not accord with the general view regarding the effects of inbreeding, since they indicate that inbreeding per se is not necessarily inimical either to fertility or to vigor. Success or failure in any series of inbreeding experiments would seem to depend on the character of the stock that is inbred, on the manner in which breeding animals are selected, and on the environmental conditions under which the animals are reared. 